J. M. A. van Gerven

A. Hovestadt

J. W. B. Moll

C. J. Rodenburg

T. A. W. Splinter

A. T. van Oosterom

L. Keizer

T. E. Drogendijk

C. M. Groenhout

Ch. J. Vecht

J. P. Neijt

\section{The effects of an ACTH (4-9) analogue on development of cisplatin neuropathy in testicular cancer: a randomized trial}

Received: 26 July 1993

Received in revised form:

1 November 1993

Accepted: 8 November 1993

J. M. A. van Gerven - A. Hovestadt

J. W. B. Moll, Ch. J. Vecht (ه)

Departments of Neurology,

Dr. Daniel den Hoed Cancer Center and University Hospital Rotterdam, P.O. Box 5201, 3008 AE Rotterdam, The Netherlands

C. J. Rodenburg - T. A. W. Splinter Department of Medical Oncology, Dr. Daniel den Hoed Cancer Center and University Hospital Rotterdam

T. E. Drogendijk

Department of Biostatistics,

Dr. Daniel den Hoed Cancer Center and University Hospital Rotterdam

A. T. van Oosterom

Department of Medical Oncology,

University Hospital Antwerpen

L. Keizer

University Hospital Leiden

C. M. Groenhout

Oragon International b.v., Oss

J. P. Neijt

Department of Medical Oncology, University Hospital Utrecht

\begin{abstract}
The efficacy of the ACTH (4-9) analogue Org 2766 in the prevention of subclinical cisplatin neuropathy was assessed in a doubleblind placebo-controlled multi-centre study in patients with testicular cancer or adenocarcinoma of unknown primary. Forty-two patients received at least four cycles of cisplatin (100 $\mathrm{mg} / \mathrm{m}^{2}$ per cycle), together with subcutaneous injections of Org 2766 ( $2 \mathrm{mg} /$ day for 5 consecutive days) or placebo. Vibratory threshold was used as a measure of neuropathy. For each individual patient, the influence of cisplatin on vibratory perception was quantified by the slope of the regression line between the natural logarithm of the vibratory thresholds and the number of cycles. From the slopes, the proportional increase of vibratory threshold per cycle of cisplatin was calculated. On average, vibratory tresholds increased by $42 \%$ with each cycle of $100 \mathrm{mg} / \mathrm{m}^{2}$ of cisplatin in the placebo group, and by $19 \%$ during treatment with Org 2766. The influence of cisplatin
\end{abstract}

on vibratory thresholds was highly significant in the placebo group $(P<0.0001)$, and of borderline significance in the group treated with $\operatorname{Org} 2766(P=0.06)$. The difference in slopes between the two groups was of borderline statistical significance (Wilcoxon's two-sample test: $P=0.06$; analysis of variance: $P=0.04)$. These results show that Org 2766 cannot completely prevent cisplatin neuropathy in young men with testicular cancer, but nerve damage may be ameliorated by the use of this ACTH (4-9) analogue.

Key words Cisplatin - Neuropathy Cancer - ACTH (4-9) analogue Org 2766

\section{Introduction}

Cisplatin is an effective chemotherapeutic agent in the treatment of a variety of malignancies, including ovarian carcinoma [1], bladder cancer [7], testicular cancer [10] and adenocarcinoma of unknown primary tumor [12]. The main side-effects of cisplatin are nephrotoxicity, myelosuppression, ototoxicity and neuropathy [5, 13]. Cisplatin neuropathy is a predominantly sensory peripheral polyneuropathy, often leading to severe sensory and proprioceptive abnormalities [4]. The neuropathy may continue to deteriorate for about 4 months after cessation of treatment, and is often not completely reversible $[6,8]$. Some studies indicate that the neuropathy is primarily caused by axonal damage of the large myelinated Ia fibres, probably at the level of the dorsal root ganglion cell [11]. Others suggest that both demyelination and axonal degeneration 
occur together [9]. Clinical neuropathy has been reported in at least $50 \%$ of patients with ovarian and testicular cancer $[2,10]$. The developement of neuropathy is related to the total amount of cisplatin received. Subclinical loss of vibratory sensation in the legs occurs after a cumulative dose of $350 \mathrm{mg} / \mathrm{m}^{2}$ [11], while clinical symptoms usually develop above a dose of $450-600 \mathrm{mg} / \mathrm{m}^{2}[1,11]$. Above $200 \mathrm{mg} / \mathrm{m}^{2}$ per cycle, peripheral neuropathy is considered to be the main dose-limiting side-effect $[5,11]$.

The ACTH (4-9) analogue Org 2766 has been reported to reduce the incidence and severity of cisplatin-induced polyneuropathy in patients treated for ovarian cancer [2]. Preliminary evidence indicates that this neuropeptide ameliorates cisplatin neuropathy by enhancing endogenous nerve repair mechanisms, rather than by protecting against the neurotoxic effects of cisplatin [6]. The aim of the present double-blind trial was to investigate the efficacy of this ACTH (4-9) analogue versus placebo in preventing sensory polyneuropathy in patients with metastatic (non-)seminomatous testicular cancer or adenocarcinoma of unknown primary who were treated with cisplatin. Vibratory perception has been shown to be a reliable and reproducible indicator of cisplatin neuropathy. Elevation of vibratory thresholds usually precedes the occurrence of symptomatic cisplatin neuropathy, and is closely related to the severity of signs and symptoms of clinically relevant polyneuropathy $[1,2,6]$. Therefore, the vibratory threshold was used as quantitative measure of subclinical peripheral sensory polyneuropathy.

\section{Patients and methods}

\section{Trial design}

The study was a multicentre, double-blind and placebo-controlled trial. Patients were treated with cisplatin $\left(20 \mathrm{mg} / \mathrm{m}^{2}\right.$ per day) and etoposide, either together or combined with bleomycin or ifosfamide ((B)EP or VIP), for 5 days every 3 weeks (mean 21 days, SD 5.5 days). The modes of administration of chemotherapy have been described previously [10]. Two milligrams of Org 2766 (provided by Organon International, Oss, The Netherlands) or placebo was subcutaneously injected during the daily courses of chemotherapy. Patients were treated with an intended number of four cycles, but extended treatment was allowed if necessitated by progression of the tumour.

\section{Patients}

Fifty-five patients were randomized for the study. Patients were required to be younger than 60 years; to have no (previous treatment of) central or peripheral nervous system metastases; to have no signs or symptoms of peripheral neuropathy, or conditions or treatments known to interfere with the peripheral nervous system (e.g. diabetes, alcohol abuse); to have no significant abnormalities of bone marrow, liver or renal function; to have a World Health Organisation (WHO) performance status of 2 or better. All patients gave informed consent to participate in this trial. The study was performed according to the requirements of the Declaration of Helsinki.

\section{Methods}

Vibratory thresholds were measured at the dorsum of the second metacarpal bone of the left hand, with a Vibrameter III (Somedic $\mathrm{AB}$, Stockholm, Sweden), by a method described previously $[1,2]$, and recorded as micrometres of skin displacement. The Vibrameter uses a vibratory frequency of $100 \mathrm{~Hz}$ and corrects for pressureinduced alterations in vibratory amplitude. Age-related normal values were obtained from the manufacturer [3]. Vibratory thresholds were to be obtained before treatment with chemotherapy (screening), after the second and fourth cycles and 3-5 months after the last cycle. In addition, the presence or absence was noted of paraesthesias, numbness, Lhermitte's sign, unsteadiness of gait, loss of dexterity and pain [9]. Severity of symptoms is indicated by the sum score of positive symptoms (range: 0-6).

\section{Statistical analysis}

Patients were considered evaluable if they had been treated with at least four cycles of chemotherapy and Org 2766 or placebo, and if at least two vibratory threshold measurements were obtained, after two separate cycles of chemotherapy. Some patients received up to five additional cycles of chemotherapy, with Org 2766 or placebo. For each patient, a linear regression analysis was performed of the natural logarithm of the vibratory thresholds with the number of cycles. Because neuropathy may develop for 3-5 months after the last cycle [6], values from this period were considered as belonging to a virtual "last cycle plus one" in the regression analysis. The slopes of both patient groups were compared by Wilcoxon's twosample rank sum test and by analysis of variance (ANOVA) with correction for age and time intervals between cycles. The significance of the slopes was assessed with the sign test. From the slopes of the regression lines, the proportional increase in vibratory threshold per cycle of cisplatin was determined. Results were expressed as mean (SD), unless indicated otherwise. Two-sided $P$ values $<0.05$ were considered statistically significant.

\section{Results}

Thirteen of the 55 randomized patients were not evaluable: 11 because fewer than four cycles were administered (mostly because of progressive disease), 2 because fewer than two neurological assessments were available. The

Table 1 Clinical characteristics

\begin{tabular}{lll}
\hline & Placebo & Org 2766 \\
\hline Number & 23 & 19 \\
Male & 22 & 19 \\
Age (years, range) & $28(18-41)$ & $29(21-52)$ \\
$\begin{array}{l}\text { Primary tumour: } \\
\quad \text { testis }\end{array}$ & 18 & 16 \\
$\quad$ unknown & 5 & 3 \\
$\begin{array}{l}\text { Total number of cycles } \\
\text { of chemotherapy: }\end{array}$ & & \\
$\quad \begin{array}{l}\text { four } \\
\text { five-nine }\end{array}$ & 18 & 16 \\
$\quad \begin{array}{l}\text { Total cumulative amount } \\
\text { of cisplatin }\left(\mathrm{mg} / \mathrm{m}^{2}\right)\end{array}$ & 5 & 3 \\
\hline
\end{tabular}




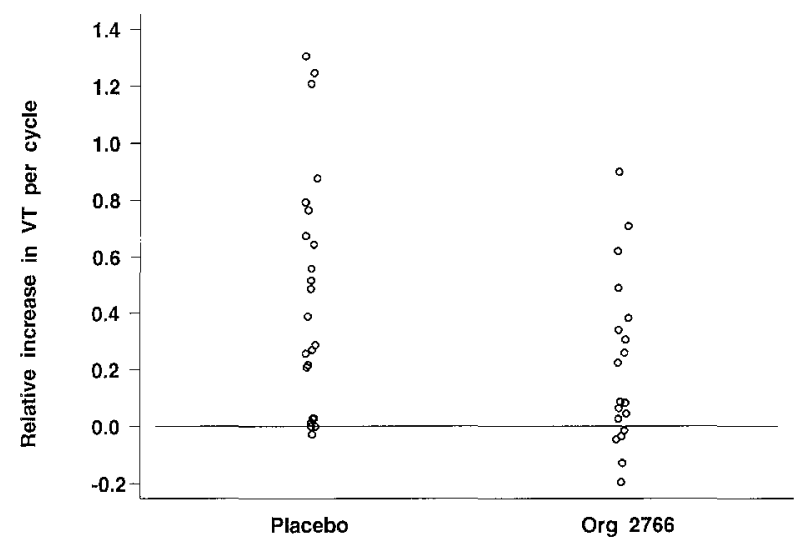

Fig. 1 Relative increase $(\mu \mathrm{m})$ of vibration threshold $(V T)$ per cycle

clinical characteristics of the remaining 42 patients are shown in Table 1. There were no differences between the clinical profiles of the two patient groups or in their chemotherapeutic regimens.

The slope of the relationship between the number of cycles of cisplatin and the natural logarithm of vibratory thresholds was $0.27(0.27)$ for all 42 patients. There was no association between age and slopes $(P>0.80$, ANOVA). On average, the slopes were considerably larger in the placebo group $[0.35,(0.28) ; P<0.0001$ by sign test] than in the group treated with $\operatorname{Org} 2766[0.17(0.24) ; P=0.06]$. This indicates that the vibratory threshold increased following each additional cycle of cisplatin $\left(100 \mathrm{mg} / \mathrm{m}^{2}\right)$, by a mean of $42 \%$ in the placebo group and by $19 \%$ in the group treated with $\operatorname{Org} 2766$. The relative increase in vibratory threshold per cycle of cisplatin is shown in Fig. 1. The difference in slopes between the two groups was significant by ANOVA, with correction for age and time interval between cycles $(P=0.04)$, but did not reach statistical significance by Wilcoxon's two-sample rank sum test $(P=0.06)$.

Subclinical neuropathy can occur at cumulative cisplatin amounts of $350 \mathrm{mg} / \mathrm{m}^{2}$, whereas clinical symptoms usually develop above $450 \mathrm{mg} / \mathrm{m}^{2}[1,11]$. Twelve patients in the placebo group and 8 patients treated with Org 2766 received no more than $400 \mathrm{mg} / \mathrm{m}^{2}$ cisplatin (four cycles) and had a vibratory threshold measurement at 3-5 months after treatment. The vibratory thresholds in these patients are shown in Table 2. Three to 5 months after treatment, vibratory thresholds had become abnormal in 9 out of these 12 placebo-treated patients $(75 \%)$ and in 4 of the 8 patients treated with Org $2766(50 \%)$.

The average symptom score was 0 out of 6 in both groups before treatment. A mean of two symptoms was present in the placebo group at 3-5 months after they had received four cycles of cisplatin. At this time, patients treated with Org 2766 reported one symptom on average (not significantly different).
Table 2 Vibratory thresholds $(\mu \mathrm{m})$ in patients treated with 400 $\mathrm{mg} / \mathrm{m}^{2}$ of cisplatin, combined with placebo or Org 2766 (Pre before or after the 1 st cycle; $>I I$ after the 2 nd or 3 rd cycle; $>I V$ after the 4th cycle; Final 3-5 months after the 4th cycle of cisplatin

\begin{tabular}{llllll}
\hline & \multicolumn{2}{l}{ Placebo } & & \multicolumn{2}{l}{ Org 2766} \\
\cline { 2 - 3 } \cline { 6 - 7 } & {$[$ mean (SD)] } & $n$ & & {$[$ [mean (SD)] } & $n$ \\
\hline Pre & $0.35(0.21)$ & 12 & & $0.45(0.29)$ & 8 \\
$>$ II & $0.41(0.22)$ & 11 & & $0.40(0.12)$ & 8 \\
$>$ IV & $0.95(0.72)$ & 9 & & $0.45(0.21)$ & 6 \\
Final & $4.03(5.06)$ & 12 & & $1.85(1.87)$ & 8 \\
\hline
\end{tabular}

In the patients treated with more than four cycles of cisplatin, vibratory thresholds increased progressively during fifth to ninth cycles. During this extended treatment, vibratory thresholds became abnormal in all 5 patients in the placebo group, and in 3 of the 4 patients treated with Org 2766. There were no untoward effects of treatment with Org 2766.

\section{Discussion}

The results of the present study show that Org 2766 (10 $\mathrm{mg} / \mathrm{cycle}$ ) does not completely prevent the increase in vibratory threshold as occurs in young patients with adenocarcinoma of unknown primary or (non-)seminomatous testicular cancer during treatment with cisplatin (100 $\mathrm{mg} / \mathrm{m}^{2}$ per cycle). There were indications, however, that Org 2766 may ameliorate cisplatin-induced polyneuropathy: vibratory thresholds increased by $19 \%$ in patients treated with the ACTH (4-9) analogue and by $42 \%$ per cycle on average in patients treated with placebo.

These results are in fair agreement with previous clinical studies of Org 2766 in the prevention of cisplatin-induced neuropathy in patients with ovarian cancer $[2,6]$. In these studies, a less than two-fold increase in vibratory thresholds occurred during treatment with Org 2766, as opposed to a more than eight-fold increase in the placebo group, after six cycles of cisplatin [2]. In our study in patients with testicular cancer, usually less than six cycles of cisplatin were administered. Nevertheless, very similar increases in vibratory thresholds were derived from the proportional elevation per cycle of cisplatin: $19 \%$ in the Org 2766-group and $42 \%$ in the placebo group amount to a 2.8-fold and an 8.2-fold increase, respectively, after six cycles. The actual values of vibratory thresholds in patients treated with four cycles of cisplatin (shown in Table 2) also suggest that Org 2766 substantially reduces the cisplatin-induced elevation of vibratory thresholds.

The very similar effects of Org 2766 in two different groups of patients provide strong indications for a truly ameliorating effect of the ACTH (4-9) analogue on cisplatin-induced polyneuropathy. The number of clinical 
signs and symptoms of neuropathy that developed in this study was too low to allow meaningful statistical analysis. In a subgroup of patients who had received the same cumulative amount of cisplatin $\left(400 \mathrm{mg} / \mathrm{m}^{2}\right)$ and who were studied within 3-5 months after treatment, patients treated with placebo reported twice as many symptoms, on average, as patients treated with Org 2766 . This suggests that Org 2766 may counteract not only subclinical but also clinically relevant cisplatin neuropathy, although studies in patients with a higher prevalence of cisplatin-induced symptoms (e.g. older patients or those receiving higher dosages of cisplatin) will be necessary to demonstrate this.
In summary, our results show that Org 2766, an ACTH (4-9) analogue, cannot completely prevent cisplatin-induced polyneuropathy in young patients with (non-)seminomatous testicular cancer or adenocarcinoma of unknown primary. This study indicates, however, that this neuropeptide can ameliorate cisplatin neuropathy to a degree that is comparable with effects seen in a previous trial of patients suffering from ovarian carcinoma [2].

Acknowledgements We thank Janet van Vliet for secretarial assistance.

\section{References}

1. Gerritsen van der Hoop R, Van Houwelingen JC, Van der Burg MEL, Ten Bokkel Huinink WW, Neijt JP (1990) The incidence of neuropathy in 395 cancer patients treated with or without cisplatin. Cancer 66 : 1697-1702

2. Gerritsen van der Hoop R, Vecht CJ, Van der Burg MEL, Elderson A, Boogerd W, Heimans JJ, Vries EP, Van Houwelingen JC, Jennekens FGI, Gispen WH, Neijt JP (1990) Prevention of cisplatin neurotoxicity with an ACTH (4-9) analogue in patients with ovarian cancer. N Engl J Med 322: 89-94

3. Goldberg JM, Lindblom U (1979) Standardised methods of determining vibratory perception thresholds for diagnosis and screening in neurological investigations. J Neurol Neurosurg Psychiatry $42: 793-803$

4. Hadley D, Herr HW (1979) Peripheral neuropathy associated with cisdichlorodiamine platinum (II) treatment. Cancer 44 : 2026-2028
5. Hamers FTP, Gispen WH, Neijt JP (1992) Neurotoxic side-effects of cisplatin. Eur J Cancer 27:372-376

6. Hovestadt A, Van der Burg MEL, Verbiest HBC, Van Putten WLJ, Vecht CJ (1992) The course of neuropathy after cessation of cisplatin treatment, combined with Org 2766 or placebo. J Neurol 239: 143-146

7. Miller RS, Torti FM (1992) Chemotherapy of advanced transitional-cell carcinoma of the bladder. Cancer Chemother Pharmacol 30 [Suppl] : S99-S110

8. Ongerboer de Visser BW, Tiessens G (1985) Polyneuropathy induced by cisplatin. Prog Exp Tumor Res 29: 190-196

9. Roelofs RI, Hrushesky W, Rogin J, Rosenberg L (1984) Peripheral sensory neuropathy and cisplatin chemotherapy. Neurology $34: 934-938$
10. Stoter G, Sleyfer DT, Ten Bokkel Huinink WW, Kaye SB, Jones WG, Van Oosterom AT, Vendrik CPJ, Spaander P, De Paauw M, Sylvester R (1986) High-dose versus low-dose vinblastine in cisplatin-vinblastinebleomycin combination chemotherapy of non-seminomatous testicular cancer: a randomised study of the EORTC genitourinary tract cancer cooperative group. J Clin Oncol 4 : 1199-1206

11. Thompson SW, Davis LE, Kornfeld M, Hilgers RD (1975) Cisplatin neuropathy, clinical electrophysiologic, morphologic and toxicologic studies. Cancer 54:1269-1275

12. Van der Gaast A, Verweij J, HenzenLogmans SC, Rodenburg CJ, Stoter G (1990) Carcinoma of unknown primary: identification of a treatable subset? Ann Oncol 119: 122

13. Von Hoff DD, Schilsky R, Reichert CM, Reddick RL, Rosencweig M, Young RC, Muffia FM (1979) Toxic effects of cis-dichlorodiammineplatinum in man. Cancer Treat Rep 63 : $1527-1531$ 